Artigo de Revisão

Hegemonia - Revista Eletrônica do Programa de Mestrado em Direitos Humanos, Cidadania e Violência/Ciência Política do Centro Universitário Unieuro

ISSN: 1809-1261

UNIEURO, Brasília, número número 27 (Especial), pp. 43-57.

Recebido em: 27/9/2018

Avaliado em: 13/10/2018

Aprovado em: 21/11/2018

\title{
O PROGRAMA NACIONAL DE PLANTAS MEDICINAIS E FITOTERÁPICOS, OS ARRANJOS PRODUTIVOS LOCAIS (APL'S) DAS AGRICULTORAS FAMILIARES E AO ACESSO AO SISTEMA ÚNICO DE SAÚDE
}

Eliana Lutzgarda Collabina Ramirez Abrahão ${ }^{1}$ e Joseane Costa Carvalho

Resumo: O acesso a fitoterapia como uma medida integrativa de saúde já é mundialmente utilizado. E no Brasil, também, está sendo aplicada à programas de saúde, em razão da diversidade de plantas medicinais, que possibilita altos níveis de oferta à demanda e à necessidade de medicamentos alternativos, o que reduz o preço das ofertas de mercado. $\mathrm{O}$ Ministério da Saúde, estimula estudos e pesquisas que aperfeiçoem propostas de saúde integrativa a partir da fitoterapia, assim como analisa propostas executadas junto ao SUS. O Programa Nacional de Plantas Medicinais e Fitoterápicos (PNPMF) apoia e incentiva o input tecnológico, sociológico e financeiro dos APL's de plantas medicinais por representar uma associação de universos, quais sejam, a academia e suas pesquisas, o setor empresarial, consolidando a biodiversidade e a indústria farmacêutica nacional. O Programa SUS ao interagir com os APL's, também se articula com a agricultura familiar, são pequenos agricultores familiares originários do Movimento dos Trabalhadores Rurais Sem-Terra, que estão inseridos ao Programa de Fitoterapia do Sistema Único de Saúde, ligados a produção de plantas medicinais. Estes agricultores receberam apoio financeiros do Programa de Pequenos Projetos eco sociais, o que garantiu a implantação de hortas, parcerias com capacitações técnicas. A necessidade de maiores informações sobre produção e comercialização. A interação universidade, pesquisa e projetos de extensão viabilizam fortalecimento da proposta. Este artigo objetiva descrever como se deu a implantação de um APL de plantas medicinais junto a assentamentos dos Sem Terra no município de Padre Berardo; e analisar o processo da construção do conhecimento desde o conhecimento tradicional até o conhecimento cientifico; e analisar como se encontra o acesso ao SUS seja para venda dos fitoterápicos dos APL's de agricultores, seja para distribuição dos fitoterápicos aos pacientes do SUS. Portanto usamos uma metodologia da pesquisa-ação, buscando não somente pesquisar mas transformar a realidade. $O$ recurso financiado pelo

\footnotetext{
1 Doutora em Educação e Docente da Universidade de Brasília.

${ }^{2}$ Doutora em Neurobiologia e Docente na Universidade Federal do Sul e Sudeste do Pará.
} 
Artigo de Revisão

Hegemonia - Revista Eletrônica do Programa de Mestrado em Direitos Humanos, Cidadania e Violência/Ciência Política do Centro Universitário Unieuro

ISSN: 1809-1261

UNIEURO, Brasília, número número 27 (Especial), pp. 43-57.

CNPq foi fundamental para a realização dos cursos, que aconteceram na sede do Assentamento Vereda 1 de Padre Bernardo, com Professores e estudantes da Universidade de Brasília e Universidade Católica. Concluímos o acesso a compra dos fitoterápicos produzidos pelos agricultores familiares não tem se realizado porque os agricultores familiares são restritos a vender a matéria prima e não conseguir superar os estágios bioquímicos e de mercado da cadeia produtiva. O que pode ser superado a partir de investimentos em cursos técnicos e investimento em equipamentos laboratoriais. $\mathrm{O}$ acesso do paciente ao SUS tem sido dificultado pelo próprio paciente que desvaloriza abordagens alternativas, o que pode ser alterado a partir de ações concientizadoras e de valorização e resgate cultural.

Palavras-Chave: Agroecologia; Prática integrativa; Fitoterapia; Plantas medicinais; SUS; Arranjos produtivos locais de plantas medicinais; Sustentabilidade; Agricultura familiar; Reforma agrária.

Abstract: Access to phytotherapy as an integrative health measure is already used worldwide. And in Brazil, too, it is being applied to health programs, due to the diversity of medicinal plants, which allows high levels of supply to demand and the need for alternative medicines, which reduces the price of market offers. The Ministry of Health encourages studies and research to improve proposals for integrative health based on phytotherapy, as well as analyzes proposals executed with SUS. The National Program of Medicinal Plants and Phytotherapics (PNPMF) supports and encourages the technological, sociological and financial input of APL's of medicinal plants because it represents an association of universes, namely academia and research, business sector, consolidating biodiversity and the national pharmaceutical industry. The SUS Program, when interacting with the APLs, also articulates with family agriculture, are small family farmers originating from the Landless Rural Workers Movement, which are part of the Herbal Health System's Phytotherapy Program, linked to the production of medicinal plants. These farmers received financial support from the Small Eco-Projects Program, which ensured the establishment of gardens, partnerships with technical skills. The need for more information on production and marketing. The interaction between university, research and extension projects makes it possible to strengthen the proposal. This article aims to describe how the implantation of an APL of medicinal plants along the settlements of the Sem Terra in the municipality of Padre Berardo; and analyze the process of building knowledge from traditional knowledge to scientific knowledge; and to analyze how the access to the SUS is to be for the sale of phytotherapeutics of farmers' APLs, or for the distribution of herbal medicines to SUS patients. Therefore we use a methodology of action research, seeking not only to research but to transform reality. The resource financed by CNPq was fundamental for the realization of the courses, which happened in the headquarters of the Vereda 1 settlement of Padre Bernardo, with professors and students of the University of Brasilia and Catholic University. We conclude access to the purchase of herbal products produced by family farmers has not been carried out because the family farmers are restricted to sell the raw material and can not overcome the biochemical and market stages of the production chain. This can be overcome through investments in technical courses and investment in laboratory equipment. The patient's access to SUS has been hampered by the patient himself who devalues alternative 
Artigo de Revisão

Hegemonia - Revista Eletrônica do Programa de Mestrado em Direitos Humanos,

Cidadania e Violência/Ciência Política do Centro Universitário Unieuro

ISSN: 1809-1261

UNIEURO, Brasília, número número 27 (Especial), pp. 43-57.

approaches, which can be altered through awareness-raising actions and valorization and cultural rescue.

Key-Words: Agroecology; Integrative practice; Phytotherapy; Medicinal plants; SUS; Local productive arrangements of medicinal plants; Sustainability; Family agriculture; Agrarian reform.

\section{INTRODUÇÃO}

$\mathrm{Na}$ última década graças a um contexto de favorecimento às políticas públicas, o Sistema Único de Saúde (SUS) implementou a prática integrativa da Fitoterapia. Historicamente em vários estados do Brasil se iniciou, de modo espontâneo ou dirigido, uma interação dos hospitais da rede pública com a fitoterapia. No Hospital Regional de Planaltina nos anos 80 iniciou-se um trabalho de farmácia viva e saúde integral. Ali funcionava uma Unidade Especial de Medicina Alternativa (UEMA), onde se construiu canteiros, espaço de atendimento ao paciente nas áreas de homeopatia, fitoterapia, acupuntura, antroposofia e psicologia, massagem chinesa, alimentação integral, e outros. E em 90 foi construído um laboratório de manipulação de medicamentos fitoterápicos distribuídos gratuitamente conforme prescrição médica. E em 2001 passou de UEMA a ser chamada de CeMA- Centro de Medicina Alternativa. Em 2011, a partir do Decreto No 33.384 o CeMA torna-se Centro de Referência em Práticas Integrativas em Saúde - CERPIS que passa a ser integrada à Diretoria Regional de Atenção Primária à Saúde (DIRAPS). E é responsável pela implementação de Práticas Integrativas e Saúde (PIS) na Secretaria de Saúde do Distrito Federal (FIOCRUZ, 2018).

Em 2006 foi instituído a Política Nacional de Plantas Medicinais e Fitoterápicas PNPMF visando o uso de plantas medicinais e fitoterápicos numa cadeia produtiva que percorre desde o cultivo, beneficiamento com sustentabilidade, até processo produtivo do medicamento fitoterápico e sua distribuição, com essa ação não só favorecia a necessidade e demanda social, mas, além disso estava favorecendo a indústria nacional (BRASIL, 2006).

O Brasil possui uma das maiores extensões de flora do mundo, e a Amazônia representa a maior reserva natural de vegetais ricos em biodiversidade e efeitos fitoterápicos. O que provoca um foco de atenções dentro da academia cientifica por permitir disseminar o uso de medicamentos fitoterápicos junto a população a partir de ações espontâneas de 
Artigo de Revisão

Hegemonia - Revista Eletrônica do Programa de Mestrado em Direitos Humanos,

Cidadania e Violência/Ciência Política do Centro Universitário Unieuro

ISSN: 1809-1261

UNIEURO, Brasília, número número 27 (Especial), pp. 43-57.

gestões politicas junto ao território nacional. Contudo, pouco se trabalhou sobre a toxicidade das plantas medicinais, o que não impede que se façam estudos ulteriores.

O acesso a fitoterapia como uma medida integrativa de saúde já é mundialmente utilizado. E no Brasil, também, está sendo aplicada à programas de saúde, em razão da diversidade de plantas medicinais, que possibilita altos níveis de oferta à demanda e à necessidade de medicamentos alternativos, o que reduz o preço das ofertas de mercado. Tornando plausível a proposta de um programa de saúde baseada na fitoterapia integrativa do Sistema Único de Saúde. O Ministério da Saúde, estimula estudos e pesquisas que aperfeiçoem propostas de saúde integrativa a partir da fitoterapia, assim como analisa propostas executadas junto ao SUS.

Este trabalho busca descrever como está o acesso dos pacientes à fitoterapia proposta pelo SUS, assim como, relatar a interação dessa proposta com a agricultura familiar que é protagonista dos arranjos produtivos locais (APL) de plantas medicinais e fitoterápicas.

Arranjos Produtivos Locais são “aglomerações de empresas, localizadas em um mesmo território, que apresentam especialização produtiva e mantêm vínculos de articulação, interação, cooperação e aprendizagem entre si e com outros atores locais, tais como: governo, associações, empresariais, instituições de crédito, ensino e pesquisa“. O mesmo fenômeno é chamado de "cluster" em outras regiões (2018, IBICT).

Os agricultores familiares oriundos dos assentamentos do MST representam uma mão de obra disponível e baixo custo que dão ótimo resultados sociais, de saúde, e produtivos frente às demandas do SUS. Assim a inclusão deste setor da sociedade, não só reduz o desemprego e a demanda do atendimento à saúde pública, como complementa e supre a necessidade produtiva de plantas medicinais.

\section{METODOLOGIA}

Foi realizada uma pesquisa qualitativa, onde buscamos descrever como se constrói o processo de produção do fitoterápico tratando desde como se dá a elaboração do conhecimento cientifico e o conhecimento tradicional, até como está o acesso ao fitoterápico 
Artigo de Revisão

Hegemonia - Revista Eletrônica do Programa de Mestrado em Direitos Humanos,

Cidadania e Violência/Ciência Política do Centro Universitário Unieuro

ISSN: 1809-1261

UNIEURO, Brasília, número número 27 (Especial), pp. 43-57.

no SUS e sua interação com os APL de plantas medicinais e os principais protagonistas do processo produtivo, quais sejam a pequena agricultura familiar oriunda do MST.

Informações sobre o MST foram colhidas a partir de entrevistas com participantes do encontro do PRONERA ${ }^{3}$ e representantes de assentamentos diversos localizados nos estados do território brasileiro, em evento realizado em Brasília no mês de junho de 2018, na Universidade de Brasília.

A pesquisa foi documental em estatutos, leis, decretos e a pesquisa foi bibliográfica em artigos acadêmicos e/ou documentos impressos ou virtuais da internet sobre atividades ligadas, APL's em assentamentos da reforma agrária, a fitoterapia junto ao SUS e Ministério da Saúde e outros.

Característica de universos de estudo:

Foram escopo do estudo agricultores de assentamentos rurais do Movimento dos Sem Terra interagindo com APL's de plantas medicinais, de três assentamentos rurais da região do Goiás.

O sistema de produção está relacionado com:

Setor de saúde em geral representado por mulheres, que desenvolvem o modus operandi desde o plantio de hortas medicinais até a elaboração do remédio, pode ter passado por controle de qualidade ou ser caseiro. Estas mulheres não se restringem a fazer os remédios, mas também fazem doces, compotas, temperos e artesanatos. Que são ofertados à venda em feiras que são organizadas por elas ou regionalmente.

Estas mulheres receberam auxilio de estudantes oriundos de Universidade de Brasília que as orientou, seja de forma técnica para melhorar a produção das hortas medicinais, seja para elaborar projetos e obter financiamentos e captação de recursos que são aplicados na horta e no processo de elaboração dos medicamentos junto ao Programa Nacional de Plantas Medicinais que busca garantir à população brasileira o acesso seguro e o uso racional de

3Programa Nacional de Educação e Reforma Agrária -" Encontro 20 anos da educação do campo e do PRONERA” - FÓRUM NATIONAL DE EDUCAÇÃO DO CAMPO. BRASÍLIA,12 A 15 DE JUNHO DE 2018.Centro Comunitário Athos Bulcão - Campus Darcy Ribeiro Universidade de Brasília.DF.. 
Artigo de Revisão

Hegemonia - Revista Eletrônica do Programa de Mestrado em Direitos Humanos,

Cidadania e Violência/Ciência Política do Centro Universitário Unieuro

ISSN: 1809-1261

UNIEURO, Brasília, número número 27 (Especial), pp. 43-57.

plantas medicinais e fitoterápicos, promovendo o uso sustentável da biodiversidade, o desenvolvimento da cadeia produtiva e da indústria nacional. Tendo como objetivo a Política e o Programa a ampliação das opções terapêuticas e melhoria da atenção à saúde dos usuários do Sistema único de Saúde

Entidades financiadoras como o CNPq tem publicado chamadas para financiar pesquisas e projetos sobre Fitoterápicos. E o Ministério da Saúde tem apoiado projetos municipais e estaduais para o uso de plantas, desenvolvimento e registro de fitoterápicos com assistência farmacêutica (Ministério da Saúde, 2018).

Os projetos devem se desenvolver ao longo de 2 anos e devem possuir um apoio técnico universitário, para controle de parasitas e conhecimentos técnicos de hortas medicinais, armazenamento, elaboração de fornos solares, técnicas hidráulicas, plantas medicinais, material pedagógico como cartilhas, e apresentações e difusão dos projetos. Também foram produzidos mapas dos assentamentos com auxílio de GPS e softer do curso de Geografia da UnB, e seus alunos.

O projeto iniciou em setembro de 2003 e foi até setembro de 2005. O recurso financiado pelo CNPq foi fundamental para a realização dos cursos e do impulso aos processos de geração de renda, foi criado um ponto de venda junto A Universidade de Brasília, onde se vende até hoje os produtos agro ecológicos diversificados, além do que os agricultores multiplicaram os pontos de venda.

Além deste trabalho foi feita uma reflexão a partir de entrevistas das assentadas sobre o que é conhecimento popular de ervas medicinais ou conhecimento tradicional e o conhecimento científico.

A investigação bibliográfica e documental buscou fazer um levantamento da prática da fitoterapia no SUS e dos documentos instituídos junto a órgão burocráticos do Estado, tais como ministérios, programas governamentais. Também levantamos documentação acadêmica tais como artigos publicados que tratavam do nosso foco de pesquisa. Usamos, também a entrevista qualitativa para obter dados sobre o conhecimento popular e o conhecimento cientifico das ervas medicinais. 
Artigo de Revisão

Hegemonia - Revista Eletrônica do Programa de Mestrado em Direitos Humanos,

Cidadania e Violência/Ciência Política do Centro Universitário Unieuro

ISSN: 1809-1261

UNIEURO, Brasília, número número 27 (Especial), pp. 43-57.

\section{RESULTADOS}

Trabalhamos com dados obtidos em três assentamentos do MST localizados na região de Goiás. Estes assentamentos: Vereda 1 foi instituído em 1999 possui 99 famílias e possui uma área de 2.063,78 ha, Água Quente foi instituído em 1998, possui 66 famílias e possui uma área de 2.829,30 e Boa Vista foi instituído em 1998, possui 145 famílias e possui uma área de 4.380,03 ha pertencentes ao Município de Padre Bernardo- Goiás. O assentamento Boa Vista Possui um Colégio que possui classes desde o nível Pré-escolar, Ensino Fundamental até Ensino Médio. O assentamento Boa Vista possui um Posto de Saúde. A região realiza processos produtivos de arroz e tem um setor de mulheres que trabalham com artesanato e ervas medicinais.

A saúde é coordenada pela associação de mulheres APAFASOC - Associação de Produtoras da Agricultura Familiar Solidária do Cerrado do Município de Padre Bernardo. Esta associação se ocupava do plantio da horta medicinal e elaboração de remédios, e organizavam a distribuição gratuita entre os assentados. Elas receberam cursos de capacitação em agroecologia, artesanato, agroindústria, transporte, comercialização e geração de renda, ervas medicinais e elaboração de remédios caseiros, e venda em feiras na comunidade e feiras externas.

Os cursos foram realizados na sede do Assentamento Vereda 1, a partir de projeto financiado pelo CNPq, com Professores e estudantes da Universidade de Brasília e Universidade Católica. Houve 180 encontros no total dos cursos e foram expedidos certificados de extensão pela Universidade de Brasília aos assentados participantes. Os cursos foram realizados ao longo de 2 anos. E houve investimentos de infraestrutura, tais como a compra de sistema de irrigação (motor para bombear água, tubos hidráulicos de PVC, irrigadores), implantação da horta orgânica, implantação de viveiro com telado para sombrear o espaço, aquisição de sementes variadas, produção de mudas, composto orgânico, verduras e ervas medicinais, elaboração de desidratador solar para desidratar plantas medicinais, temperos e frutas, compra de cozinha industrial, panelas, utensílios, vidros para armazenamento de compotas de frutas.

Ocorreu o plantio e coleta dos seguintes plantas medicinais. 
Artigo de Revisão

Hegemonia - Revista Eletrônica do Programa de Mestrado em Direitos Humanos,

Cidadania e Violência/Ciência Política do Centro Universitário Unieuro

ISSN: 1809-1261

UNIEURO, Brasília, número número 27 (Especial), pp. 43-57.

Guaco (Mikania glomerata) e Espinheira-santa (Maytenus ilicifolia), Alcachofra (Cynara scolymus), Aroeira (Schinus terebenthifolius), Cáscara-sagrada (Rhamnus purshiana), Garra-do-diabo (Harpagophytum procumbens), e Unha-de-gato (Uncaria tomentosa). Agrião (Nasturtium officinalis), Alfazema (Lavandula spp), Alecrim (Rosmarinus officinalis), Alho (Allium sativum), Arnica (Arnica Montana), Babosa (Aloe vera), Boldo do Chile (Peumus boldus), Calêndula (Calendula officinalis), Carqueja (Baccharis genistelloides), Coentro (Coriandum sativum), Confrei (Symphytum officinale),

Dente de leão (Taraxacum officinale), Erva cidreira (Melissa officinalis), Erva doce (Pimpinella anisum), Hortelâ-pimenta ( Mentha piperita), Pata-de-vaca (Bauhinia forficata), Pimenta (Capsicum spp), Pitanga ( Eugenia uniflora).

Passamos pelos seguintes fases financiamento do projeto pelo CNPq, observação e analise do conhecimento tradicional, cultivo e manejo das hortas medicinais, produção de remédios caseiros, comercialização.

\section{DISCUSSÃO}

\section{O CONHECIMENTO CIENTÍFICO E O CONHECIMENTO TRADICIONAL}

Esta parte foi escrita a partir da entrevista e observação das mulheres assentadas e a tentativa de elaborar uma exposição das contradições e paralelismos entre o que é a representação do conhecimento popular sobre plantas medicinais construído na práxis do dia a dia e da herança cultural repassado de avó para mãe, de mãe para filha; e o conhecimento científico elaborado na academia.

As mulheres do assentamento traziam consigo respostas buscadas e compreendidas no seu imaginário por instinto natural. Respostas às vezes herdadas da convivência cultural local ou mesmo de seus antepassados. Bachelar, Piaget e Bruner diziam que essas respostas ou representações são conceitos "já existentes" no individuo a respeito de um certo fenômeno (apud Astolfi e Develay, 1991). É também chamada de obstáculo epistemológico ou conceito que gera o conflito cognitivo, quando deparado com o conceito científico. 
Artigo de Revisão

Hegemonia - Revista Eletrônica do Programa de Mestrado em Direitos Humanos,

Cidadania e Violência/Ciência Política do Centro Universitário Unieuro

ISSN: 1809-1261

UNIEURO, Brasília, número número 27 (Especial), pp. 43-57.

Todo processo de aprendizagem vem interferir com um conceito “já existente”, mesmo que falso cientificamente. Por essa razão, antes de entrar em campos conceituais das ciências é fundamental que haja uma integração entre professor e aluno, para que possa transformar a pré-concepção.

Foi assim que a ciência evoluiu, a busca incessante do "conhecimento verdadeiro" levou os filósofos a questionarem as teorias levantadas e a proporem novas ideias, bem como um avançado centro de estudos que discutiam as diferentes ciências e era composto por elas, o que atraiu grandes intelectuais da época.

A ciência e a tecnologia colaboraram na compreensão do universo e suas transformações. A ciência natural se caracteriza segundo Thomas Kuhn, por rupturas. Assim a ciência, ao longo da história não teve um percurso linear. Ao contrario foi um percurso caracterizado de idas e vindas, progressos e retrocessos, conflitos cognitivos, até o estabelecimento de uma teoria. Mas esta rege aquele período até que seja derrubada por outras.

O conhecimento também está relacionado a uma ideologia de classe do dominante, LEFF (2010) descreve que a ciência moderna emergiu das transformações ideológicas e do surgimento do capitalismo.

Com a industrialização o capitalismo e a ciência promovem a alienação dos trabalhadores, dando lugar à exploração da mais valia das classes oprimidas.

Contudo quando nos deparamos com um celular nota-se o impacto da tecnologia e ciência cristalizada naquele objeto, o que nos faz invalidar todo um conhecimento tradicional, por este conhecimento chamado de científico.

O academicismo farmacológico é o mais inovador, a cada ano novas doenças são diagnosticadas em laboratórios e são descobertas suas curas. E se trava um conflito entre o conhecimento popular e o conhecimento farmacêutico.

A evolução do remédio à base de ervas foi no empirismo, experimentava-se tudo, de fruta a raiz, casca. Descobriu-se que certas plantas seriam remédios potentes e outros venenos mortais. Também a observação dos animais se alimentando ou quando ficam doentes o que comem certas plantas que lhes suprem a necessidade. Assim a humanidade foi registrando esta experiência. Os registros apontam que há mais de 4.500 anos o imperador chinês Shen Nung catalogou um compendio de ervas medicinais, no Vale Indu, na mesma época surge a medicina Ayurvédica a partir do sábio Bhardvaja e Agnivesa que escreveu este 
Artigo de Revisão

Hegemonia - Revista Eletrônica do Programa de Mestrado em Direitos Humanos,

Cidadania e Violência/Ciência Política do Centro Universitário Unieuro

ISSN: 1809-1261

UNIEURO, Brasília, número número 27 (Especial), pp. 43-57.

conhecimento. Também se acredita que a escola egípcia de medicina fundada em Alexandria em 300 a.C. acumulou vasto conhecimento, que foi queimado no sec. IV d.C. por fanáticos religiosos. Com o advento da descoberta do novo mundo nativos americanos tinham conhecimento rico e confiável do valor medicinal e centenas de plantas indígenas. Até 200 anos atrás a farmacopeia médica era apenas um compendio botânico. Foi em inicio do sec. XIX que F.W.A. Sertumer extraiu cristais brancos do pó de ópio para fazer cães dormirem. O pó chamou-se morfina- alcalóide isolado do ópio, e depois extraiu-se a cocaína da folha de coca, planta que os Incas cultivavam e consideravam sagrada e a quinina extraída da quina usada no tratamento da malária e de arritmias cardíacas. E assim foi desenvolvendo-se o conceito farmacológico, e hoje um médico ocidental não reconhece um chá de uma erva com seu efeito terapêutico, e prefere oferecer um medicamento (SIMON, 1951).

Portanto é na interação prática, ou experiência de vida que a assentada, ou o grupo de assentadas, ao se relacionar com as plantas e a diversidade da flora, constrói um préconceito sobre ele, definindo-o como alimento, remédio, ou mesmo veneno(CAMARGO, 2014, p.39).

Segundo o conhecimento Ayurveda, no Vale Indus, na índia os videntes acreditavam que a sabedoria das plantas medicinais tinha sido um presente dos deuses como compaixão às doenças da humanidade. Os farmacêuticos e químicos no intuito de buscar alternativas à resistência de bactérias e vírus, muitas vezes criada pelo medicamento, lutam incessantemente, buscando novas alternativas de medicamentos e não veem que as plantas podem dar a resposta (SIMON, 1951).

Faz-se necessário um novo modelo de desenvolvimento sustentável e holístico, pois hoje o Brasil vive uma crise, sendo obrigado a produzir e consumir drogas inventadas por multinacionais. Que nem sempre temos o recurso para pagar e nem resolvem nossas doenças. Quando a biodiversidade de plantas está sendo estudada e explorada por multinacionais.

Também, há doenças como o câncer que são atribuídas ao uso de agrotóxicos, seja na manipulação da lavoura, ou na alimentação de produtos contaminados. Também se fala no estres da vida cotidiana, com excessos de trabalho, de situações desgastantes. Em fim a medicina deve ser principalmente, preventiva. E este é o último papel atribuído à medicina. 
Artigo de Revisão

Hegemonia - Revista Eletrônica do Programa de Mestrado em Direitos Humanos,

Cidadania e Violência/Ciência Política do Centro Universitário Unieuro

ISSN: 1809-1261

UNIEURO, Brasília, número número 27 (Especial), pp. 43-57.

O CONHECIMENTO CIENTÍFICO E SUA APROPRIAÇÃO DAS PLANTAS MEDICINAIS

O ressurgimento da cura pelas plantas tem sido a proposta do novo paradigma onde a medicina natural tem sido o centro das atenções. Não se trata de um fracasso da abordagem científica, que obteve grandes avanços no campo da bioquímica, fisiologia, genética e farmacologia. Quantas doenças letais infantis foram erradicadas, no entanto, persiste uma frustração quanto ao sistema de saúde, ao qual boa parte da população não tem acesso.

Nota-se pelo depoimento dos assentados que, há uma identificação cultural destes povos com o uso das plantas medicinais, talvez, porque na origem estes têm fortes traços com grupos tradicionais, quais sejam, ribeirinhos, quilombolas, camponeses, indígenas e outros, os quais sempre estiveram em relação de equilíbrio com a natureza.

Esta, conhecida como medicina popular ou medicina tradicional, permite a utilização de várias espécies da flora brasileira para fins medicinais, sendo utilizada por comunidades tradicionais; mas nas últimas décadas tem sido instrumento utilizado, também, pela ciência moderna.

A descoberta do princípio ativo em cada planta e seu isolamento, uma vez que é determinada a estrutura química o que permitirá a reprodução do medicamento sintético e comprovada a sua atividade biológica, coloca-se em risco a importância das plantas, já que os grandes laboratórios guiados pelo interesse econômico, digamos não necessitam das plantas, mas de sua estrutura química do princípio ativo, o qual eles já detêm (CAMARGO, 2014, p. 34).

A planta medicinal pode-se descartar, mas o custo da preparação do produto é inserido no preço final (BARBOSA, 2009, p. 23).

Em 1978 a Organização Mundial da Saúde passou a reconhecer o uso do fitoterápico pela sua capacidade curativa. As plantas medicinais para a OMS representam grande importância na assistência farmacêutica e no âmbito sanitário. As práticas tradicionais da Saúde atingem $80 \%$ da população mundial e dessas práticas tradicionais $85 \%$ são 
Artigo de Revisão

Hegemonia - Revista Eletrônica do Programa de Mestrado em Direitos Humanos,

Cidadania e Violência/Ciência Política do Centro Universitário Unieuro

ISSN: 1809-1261

UNIEURO, Brasília, número número 27 (Especial), pp. 43-57.

fundamentadas nas plantas medicinais. É nos países em desenvolvimentos os onde se situa 67\% das espécies vegetais (ALONSO, 1998 apud MINISTÉRIO DA SAÚDE, 2006, pg. 8).

\section{CONCLUSÃO}

Em conformidade com a OMS, foi formulada uma Política Nacional de Prática Integrativas e Complementares que instituía a fitoterapia como terapia complementar no SUS; e em 2008 foi criado um Programa Nacional de Plantas Medicinais e Fitoterápicos tendo como princípios segurança e eficácia na saúde pública, a conciliação de desenvolvimento socioeconômico e a conservação ambiental, tanto no âmbito local como em escala nacional (Ministério da Saúde, 2009).

O PNPMF está associado a um modelo de desenvolvimento sustentável que preconize a diversidade regional e ambiental, bem como o uso sustentável das plantas medicinais em todo âmbito, seja caseiro, arranjos produtivos, fitoterápicos, quanto industrial.

O modelo biomédico e a concentração do mercado produtivos nas indústrias farmacêuticas e de equipamentos representam ainda os grandes desafios a serem superados. Os marcos regulatórios só podem ser atingidos pela indústria farmacêutica, os pequenos produtores mesmo inseridos ao APL não conseguem atingir os marcos regulatórios que são muito estritos, ficando restritos a vender a matéria prima e não conseguir superar os estágios bioquímicos e de mercado da cadeia produtiva. Além disso, resta o perfil do médico ocidentalizado, que só está preparado para receitar drogas bioquímicas, e observa a doença sob a ótica da modernidade, com aparelhos tecnológicos para exames, quando certas doenças podem ser detectadas pelo toque e observação e pulsação, e finalmente o próprio paciente que desvaloriza abordagens alternativas.

Concluímos o acesso a compra dos fitoterápicos produzidos pelos agricultores familiares não tem se realizado, porque os agricultores familiares são restritos a vender a matéria prima, isto é a planta vegetal, e não conseguem superar os estágios bioquímicos e de mercado da cadeia produtiva. O que pode ser superado a partir de investimentos em cursos técnicos, capacitações e investimento em equipamentos laboratoriais. O acesso do paciente ao SUS tem sido dificultado pelo próprio paciente que desvaloriza abordagens alternativas, o que pode ser alterado a partir de ações conscientizadoras e de valorização e resgate cultural. 
Artigo de Revisão

Hegemonia - Revista Eletrônica do Programa de Mestrado em Direitos Humanos,

Cidadania e Violência/Ciência Política do Centro Universitário Unieuro

ISSN: 1809-1261

UNIEURO, Brasília, número número 27 (Especial), pp. 43-57.

Contudo, foi uma forma de realizar o uso sustentável da biodiversidade local e o acesso seguro das plantas medicinais aliadas à geração de mercado de trabalho para um setor que se encontrava às margens da política social, as mulheres agricultoras familiares assentadas da reforma agrária. Outrossim, a criação da associação representou um passo decisivo para criar um espaço para a geração de renda e comercialização.

Assim cabe ao governo realizar certos ajustes, pois apesar dos desafios muito se tem feito dentro das Políticas e Programas lançados facilitando o acesso à fitoterapia do SUS associado à consolidação da Agricultura Familiar e a Geração de renda.

\section{REFERÊNCIAS}

ARANHA, Maria Lucia de Arruda. Filosofando: introdução à filosofia/ Maria Lúcia de Arruda Aranha, Maria Helena Pires Martins. - 4. Ed.- São Paulo: Moderna, 2009.479p.

CAMARGO, Maria Thereza Lemos de Arruda. As plantas medicinais e o sagrado: a etnofarmacobotânica em uma revisão historiográfica da medicina popular no Brasil/Maria Thereza Lemos de Arruda Camargo. 1ª ed. - São Paulo: Ícone, 2014.

BARBOSA, Wagner Luiz Ramos. Fitoterapia popular e ciência farmacêutica. $1^{\text {a }}$ edição. Belém: NUMA/UFPA, 2009. 169p.

BRASIL, Ministério da Saúde. Secretaria de Ciência, Tecnologia e Insumos Estratégicos. Departamento de Assistência Farmacêutica. Politica Nacional de Plantas medicinais e Fitoterápicos. Brasília: Ministério da Saúde. 60 p. 2006. Site: $<$ http://portalms.saude.gov.br/acoes-e-programas/programa-nacional-de-plantasmedicinais-e-fitoterapicos-ppnpmf/politica-e-programa-nacional-de-plantas-medicinais-efitoterapicos/projetos-apoiados>. Acesso em 20 jul.2018.

BRASIL. Ministério da Saúde. Secretaria de Ciência, Tecnologia e Insumos Estratégicos. Departamento de Assistência Farmacêutica. Política nacional de plantas medicinais e fitoterápicos / Ministério da Saúde, Secretaria de Ciência, Tecnologia e Insumos Estratégicos, Departamento de Assistência Farmacêutica. - Brasília: Ministério da Saúde, 2006. 60 p. - (Série B. Textos Básicos de Saúde) 
Artigo de Revisão

Hegemonia - Revista Eletrônica do Programa de Mestrado em Direitos Humanos,

Cidadania e Violência/Ciência Política do Centro Universitário Unieuro

ISSN: 1809-1261

UNIEURO, Brasília, número número 27 (Especial), pp. 43-57.

BRASIL. Ministério da Saúde. Secretaria de Atenção à Saúde. Departamento de Atenção Básica. Política Nacional de Práticas Integrativas e Complementares no SUS - PNPIC-SUS / Ministério da Saúde, Secretaria de Atenção à Saúde, Departamento de Atenção Básica. Brasília: Ministério da Saúde, 2006. 92 p. - (Série B. Textos Básicos de Saúde)

DELIZOICOV, Nadir Castilho. O movimento do sangue no corpo humano: história e ensino. Tese (Doutorado em Educação), Universidade Federal de Santa Catarina, Florianópolis, 2002.

FERNANDES, Tania Maria. Plantas medicinais: memória da ciência no Brasil. Rio de Janeiro: editora Fiocruz, 2004. 260p.

FIOCRUZ-Centro de Referência em Práticas Integrativas em Saúde -CERPIS, Brasil, 2018. acesso em 2018: http://www.ideiasus.fiocruz.br/portal/index.php/praticas-integrativas-ecura/1021-centro-de-referencia-em-praticas-integrativas-em-saude-cerpis)

FINLEY, Mark. Viva com esperança: segredos para ter saúde e qualidade de vida. Gazeta: Tatuí - Casa Publicadora Brasileira, 2014. 111p.

IBICT-Instituto Brasileiro de Ciência e Tecnologia, Observatório Brasileiro de APLs. Site disponível em: <http:// www.portalapl.ibict.br)>. Acesso em 20 jul.2018.

KRASILCHIK, Myriam; MARANDINO, Martha. Ensino de ciências e cidadania. $2^{\mathrm{a}}$ Edição. Editora Moderna, 2007. 87p.

LEFF, Enrique. Epistemologia ambiental - 5ª Edição. São Paulo: Cortez, 2010. 240p.

LIMA, Durval Stockler de. Nutrição orientada: os remédios da natureza. $7^{a}$ Edição. Casa Publicadora Brasileira, 1986. 260p.

Ministério da Saúde. Secretaria de Ciência, Tecnologia e Insumos Estratégicos. Departamento de Assistência Farmacêutica. Politica Nacional de Plantas medicinais e Fitoterápicos. Site: <http://portalms.saude.gov.br/acoes-e-programas/programa-nacionalde-plantas-medicinais-e-fitoterapicos-ppnpmf/politica-e-programa-nacional-de-plantasmedicinais-e-fitoterapicos/projetos-apoiados > . Acesso em 20 jul.2018. 